\title{
The Extroverted Vs. the Introverted Personality and Second Language Learning ${ }^{1}$
}

Paula Kezwer

There have been a number of studies done to try to explain the effects of outgoingness versus reservedness on second language learning. The results of these studies have often been contradictory with some showing a clear correlation between extroversion and success in learning a second language, others failing to demonstrate that there is a positive correlation between outgoingness and second language proficiency. This paper presents a survey of all the major studies dealing with the influence of extroversion on second language learning. It is argued that among the reasons for the discrepancies in research results are the wide variety and dubious validity of the personality assessment instruments used; the nature of the tasks used to determine second language proficiency; and the structure of classroom interaction. The implications of extroversion and introversion for classroom teaching are also considered.

\section{INTRODUCTION}

Instinctively, many second language teachers somehow feel that a student with an outgoing personality is more likely to be successful as a second language learner than his less gregarious counterpart. Language teachers reason that the extrovert will create more situations for himself to engage in conversation in the target language. This enrichment of opportunities to speak the new language will positively affect the development of the student's proficiency in it.

Of course, an intuitive feeling about the relationship between an outgoing personality and second language learning is not sufficient evidence on which to base a theory of teaching and learning. A number of empirical studies have been done to try to explain the effects of outgoingness versus reservedness on second language acquisition. Some studies have shown a clear correlation between extroversion and success in acquiring a second language. However, a number of researchers have failed to demonstrate that there is any substantial connection between a extroverted personality and language learning. Still other studies have reached the opposite conclusion: that there is a negative correlation between the two. 
It would seem that the clearest idea to emerge from this tangle of results is that the relationship between extroversion and second language learning is a murky one indeed. This paper will review the major studies on the effects of extroversion vs. introversion on language learning. It will attempt to offer explanations as to why the results have been so contradictory. And finally, it will deal with the implications of the extroverted and introverted personality for classroom second language teaching.

\section{REVIEW OF THE LITERATURE}

A number of studies have shown a positive correlation between extroversion and second language learning. Pritchard (1952) used thirty-three British schoolboys studying French as subjects to test his hypothesis that there is a positive correlation between sociability and successful acquisition of a foreign language. He observed his subjects in the playground of the school and rated them on three measures of sociability: engagement in friendly horseplay, spontaneous entry into a game with another boy, and conversational approaches to other children. A positive correlation was found between sociability and scores on a French fluency test.

Chastain (1975) tested college students in beginning level classes of French, German and Spanish to investigate the relationship between a reserved/outgoing personality and success in foreign language acquisition. The criterion used to determine this success was the final course grade. Overall among the language students, the correlation between an outgoing personality and success in the course was positive.

In his 1976 doctoral dissertation, Rossier tested fifty Spanish-speaking high school students of English as a Second Language, appraising only their oral English skills. He found that extroversion was a significant variable in the development of his subjects' language proficiency.

Tucker, Hamayan and Genesee (1976) found that the more outgoing adventurous students in a one-year late (grade 7) French immersion program performed better on tests of listening comprehension and oral production than did the quieter students. As well, they found that an outgoing personality seemed to be more important for students in a late immersion program than for those who had been exposed to a French immersion curriculum since kindergarten.

The subjects in the study by Cathcart, Strong and Wong-Fillmore (1979) were twelve kindergartners and eight first and second grade pupils, all of whom were learning English as a second language. Assesesment of the subjects' language proficiency included not only standard tasks, but also observation of the natural unelicited classroom language of the subjects. Outgoingness was found to correlate with language proficiency for the first and second graders. 
Strong (1983) studied thirteen Spanish-speaking kindergartners over a period of one year. He found a correlation between the three personality traits of talkativeness, responsiveness and gregariousness, and success in learning a second language.

In contrast to the above, a sizeable group of studies have reported that no significant relationship was discovered between an outgoing personality and success in learning a second language. In Chastain's 1975 study, the results showed that among the students of French there was no significant link between a reserved/outgoing personality and success in language learning. However, in the German and Spanish classes the correlation was substantial.

In a study of kindergarten pupils done through the auspices of the Bilingual Education Project at O.I.S.E., Swain and Burnaby (1976) did not discover any link between gregariousness and second language learning. Among the nine personality characteristics they investigated, the only traits which correlated positively with second language performance were perfectionist tendencies and quickness at grasping new concepts.

Suter's work in 1977 measured the influence of a large group of variables on the accuracy of English pronunciation of non-native speakers of English. Among the many variables tested were age of taking up residence in an English-speaking country, amount of conversation carried out with native speakers of English, native language, sex, and total number of years of formal classroom training in the second language. The one personality factor examined was extroversion/introversion. This study found that the most important predictor variable of accuracy in English pronunciation was native language. Extroversion was not found to be a factor at all in achieving better English pronunciation.

In their comprehensive study of cognitive and personality traits and their effects on second language learning, Naiman et al. (1978) concluded that there was no significant correlation between extroversion and successful second language acquisition among the high school French students who were the subjects of their research.

While the researchers Cathcart et al. did find in their above mentioned work that outgoingness was a factor in the development of language proficiency for their grade one and two pupils, they also concluded that at the same time, it was not influential in the language learning success of their kindergarten subjects.

Finally, in 1984, Scheibner-Herzig and colleagues also did not find any significant correlation between extroversion and the second language performance in English of West German high school students.

As if these two opposing camps of findings were not enough to present a thoroughly inconclusive picture of the extroversion-language learning connection, the subject is further complicated by several researchers who 
have presented results to the effect that extroversion is actually detrimental to success in learning a foreign language. Smart et al. (1970) found that extroversion correlated negatively with achievement. The overachievers among the intermediate university French students who comprised their body of subjects scored higher for introversion than did the underachievers.

Expressing this same trend, Wong-Fillmore (1983) noted that among the good and poor language learners in her study, there were both gregarious and reticent types represented in each category.

The foregoing brief review of the literature has shown that there exists a controversy regarding the effects of an outgoing personality on second language learning. The next section of the paper will present several theories as to why the results obtained by the various studies have been so divergent. Three facets of the studies will be dealt with: the personality measures used; the language proficiency measures employed; and the conduct of the language classes under investigation.

\section{THE PERSONALITY MEASURES}

One reason for the nonconformity of results among the studies may well be the diversity of personality tests used to measure extroversion and introversion. With the exception of Naiman et al., Rossier and Suter (who only looked at effects on pronunciation), no other studies in this paper used the same personality measure to determine the degree of extroversion exhibited by the subjects. Interreliability correlations are not available among the various tests. As well, some methods used to measure personality were much more empirical than others. The following chart presents a rundown of the different measures of personality employed in the various studies.

\section{Table 1}

Study

Pritchard (1952)

Smart (1970)

Chastain (1975)

Rosier (1976)

Measure Used to Rate Subjects' Degree of Extroversion/Introversion

Researcher observed subjects at play in schoolyard and rated them on 3 measures of sociability: engagement in friendly horseplay; spontaneous entry into a game with another child; conversational approach to another child

Omnibus Personality Inventory (1962)

Marlowe-Crowne Scale (1964)

Eysenck Personality Inventory (1963) 
Swain \& Burnaby (1976)

Tucker et al. (1976)

Suter (1977)

Naiman et al. (1978)

Cathcart et al. (1979)

Strong (1983)

Scheibner-Herzig et al. (1984)
Classroom teachers evaluated subjects' personalities using an undescribed instrument developed by the Bilingual Ed. Project at O.I.S.E.

Junior-Senior High School Personality Questionnaire, Form B (1968)

Eysenck Personality Inventory (1963)

Eysenck Personality Inventory (1963)

Observation by the subjects' teachers

Early School Personality Questionnaire (1966) and rating by the observers

Personality-Interests Test (1972)

As can be seen in Table 1, the overwhelming majority of the formal tests of personality used to measure the subjects' tendency for extroverted or introverted behaviour were different. Although they were all tests of the self-reporting questionnaire variety, even a partial review of the types of questions contained in them will illustrate that they neither all necessarily define extroversion in the same way, nor do they attempt to measure the same thing.

The Omnibus Personality Inventory (1962), comprises 14 personality scales, the seventh of which is termed the Social Extroversion Scale. Forty of the 385 true/false questions contained in the inventory relate to the Social Extroversion Scale. The following are some examples of the questions represented in this scale.

- I take an active part in group or class discussions. ( $\$ 2)$

- I do not introduce myself to strangers at social gatherings. (\#12)

- I prefer to eat in a small rather than a large restaurant or cafeteria. (\#14)

- I am a better listener than conversationalist. ( $\# 37)$

- I prefer to stay at home rather than attend social affairs. (\#74)

- I hesitate to borrow money or personal belongings from others. (\#81)

- When I work, I prefer to be alone rather than have others around me. (\#160)

- I prefer to work with others rather than alone. $(\# 214)$

This scale seems to concentrate heavily on a person's degree of shyness, and on his preferences for being alone or in a group. Perhaps for those of us without a background in clinical psychology, it is hard to understand why questions such as $\# 14$ and $\# 81$ would bear on an individual's degree of extroversion; nevertheless, according to this scale, they do.

If we now turn to the Eysenck Personality Inventory (1963), we can immediately see that it defines outgoingness in a different way than the OPI, and thus chooses to represent extroversion with different behaviours. Here are some examples from the Extroversion Scale of the EPI, which comprises 24 questions. 
- Are you usually carefree? ( $\# 3$ )

- Do you stop and think things over before doing them? (\#5)

- Do you generally do and say things quickly without stopping to think?(\#8)

- Would you do almost anything for a dare? (\#10)

- Do you often do things on the spur of the moment? (\#13)

- Generally, do you prefer reading to meeting people? (\#15)

- Are you mostly quiet when you are with other people? (\#29)

- Do you like doing things in which you have to act quickly? (\#39)

- Can you easily get some life into a rather dull party? (\#53)

- Do you like playing pranks on others? (\#56)

The Omnibus Personality Inventory concentrates on defining extroversion in terms of such behaviours as preference for being alone or with others and talkativeness. The Eysenck Personality Inventory however, seems to gauge that adventurousness, impulsiveness, and a leaning towards practical jokes are the behaviours typical of an extroverted personality. Inter-reliability figures would be needed to see if in fact they are both predictive of the same type of personality.

In regard to the Marlowe-Crowne Scale (1964), used by Chastain in his work with college students, this scale does not really measure outgoing or inner-directed behaviour at all. The Marlowe-Crowne Social-Desirability Scale was developed in order to deal with the well-known problem that subjects tend to depict themselves in a better light when completing a self-reporting psychological test. The Marlowe-Crowne Scale attempts to control for this phenomenon by measuring a person's need for social approval and his desire for conformity. Here are some sample questions from the 33-item Marlowe-Crowne Scale.

- Before voting I thoroughly investigate the qualifications of all the candidates. (\#1)

- I sometimes feel resentful when I don't get my way. (\#6)

- I can remember "playing sick" to get out of something. (\$14)

- I always try to practice what I preach. (\#17)

- There have been times when I was quite jealous of the good fortune of others. ( $\# 28)$

It is difficult to comprehend why Chastain would have chosen the Marlowe-Crowne Scale to measure extroversion, since this is not at all what it purports to do.

Availability and brevity preclude the consideration of all the standardized tests used to measure extroversion/introversion in the various studies. It is sufficient to see that almost every test administered was different, and that at least one was not suitable for measuring extroversion at all. The literature thus lacks the credence that would be given to results replicated in different studies while using the same testing instruments. As well, some of the studies relied on observational ratings to determine the 
degree of extroversion among the subjects. This diversifies even more the methods used, and further dilutes the inter-reliability among the results of the studies.

In his work, Strong used both a standardized assessment instrument (the Early School Personality Questionnaire) and observers' ratings to assess outgoingness. He found that the ratings did correlate with proficiency, but the scores on the ESPQ did not. He suggests that this is due to the fact that many of the childrens' answers on the questionnaire did not correspond with their behaviour as observed by their teachers. They may have wanted to give a favourable presentation of themselves on the questionnaire, which did not match what they were really like. Strong suggests that for this reason it may be misleading to rely solely on self-reporting scales when assessing personality. Naiman et al. corroborate this point with their finding that students' scores on the extroversion scale very often did not bear any relationship to the investigators' personality assessments based on long hours of classroom observation.

\section{THE PROFICIENCY MEASURES}

A parallel problem exists among the studies in that they all utilized different criteria for determining the subjects' proficiency or degree of success in dealing with the second language. As with the personality measures, a multiplicity of standardized tests and oral elicitation techniques were employed. The following table illustrates the wide variety of means employed to measure second language proficiency.

Table 2

Study

Pritchard

Smart

Chastain

Rossier

EXTROVERTED VS. INTROVERTED

\section{Measure Used to Determine Language Proficiency}

French fluency test: the time during which students spoke comprehensible French in answer to a series of simple questions, pronunciation and grammatical errors being disregarded

Final grade point average in intermediate college French course

Final course grades in beginning collegelevel French, German and Spanish courses

Pictorial Stimulus Test 
Swain \& Burnaby

Tucker et al.

Suter

Naiman et al.

Cathcart et al.

Strong

Scheibner-Herzig et al.
Battery of tests including: Test de Rendement en Francais; Test of Comprehension and Production; French Comprehension Test

Test battery including: Test de Rendement en Francais; California Achievement Test (in French); oral interview; listening comprehension test

Rating of pronunciation recorded on tape International Association for the Evaluation of Educational Achievement Test of French; taped imitation task

Observation notes; storytelling and imitation tasks; 20-minute oral interview

Oral interview; examination of transcripts of unelicited playtime speech; 3 independent paid judges rated pronunciation

Informal English test developed by the researchers consisting of 80 multiple choice items

We confront once again here the problem of reliability and validity among the myriad of tests given. Some studies assessed language proficiency by means of a final course grade; however we are given no information as to what the courses entailed or how the final mark was arrived at. Other studies employed standardized measures such as the Test de Rendement en Francais, while still others relied on less formalized assessment measures such as oral interviews or proficiency test developed specifically for the study.

For example, Pritchard used as his assessment instrument a measurement of the time his subjects were engaged in speaking French in answer to a number of questions. He did not consider accuracy in structure or pronunciation as part of his rating. Thus his results may reflect the fact that the extroverted students simply were inclined to talk more in any language, but not necessarily that they were more proficient in French. It seems that what he was really testing was just whether some of the pupils were more extroverted than others.

As if all of this were not confusing enough, Strong introduces a whole other dimension into the problem with his claim that certain language elicitation procedures favour extroversion. Strong believes that the contradictory results among the studies are due to the fact that two types of language proficiency have been assessed. In some studies "natural communicative language" (NCL) is measured, by which is meant language 
used for real interpersonal communication. In other studies "linguistic task language" (LTL), language measured by a formal test, is assessed. (This categorization dovetails nicely with the work of Cummins in 1980, who proposed two distinctions in language proficiency: BICS - basic interpersonal communicative skills, and CALP - cognitive/academic language proficiency.) Strong maintains that personality factors correlate with NCL but not necessarily with LTL. In accordance with his theory, he used only NCL measures in his study to assess the relationship between the children's personalities and second language acquisition. He found that talkativeness and gregariousness did positively influence second language proficiency. However, he did not use any LTL measures at all to evaluate his subjects, and thus we have no basis of comparison by which to judge his claims.

It is interesting to note that Strong's hypothesis ties in with the whole cognitive vs. communicative issue which is under dispute at the present time in the field of second language learning and teaching. It is yet another manifestation of the dichotomy between formal language "learning" and informal, communicative language "acquisition" (Krashen 1981).

Strong would assert that experimenters such as Swain and Burnaby, Smart and Scheibner-Herzig and colleagues did not find any significant positive relationship between extroversion and second language learning because they all used formal "linguistic task language" measures to assess their subjects' language proficiency. It thus follows from his theory that Pritchard, Rossier and Strong did discover that extroversion influences second language acquisition because they used natural communicative language elicitation tasks.

A review of the literature shows there are some exceptions to Strong's hypothesis. Chastain used what Strong classifies as LTL measures to assess his students (their final course grades). He found that while the French students' success was not affected by their level of extroversion, the German and Spanish students' progress was. It has already been noted that Chastain's instruments for assessing the degree of outgoingness were rather dubious, and it would seem that this factor in itself is enough to prejudice the results. In addition, we do not know what the final course grades consisted of, nor do we know, as Chastain points out, whether a final grade is really an indication of proficiency at all.

Tucker et al. also sample linguistic task language in their study and they obtained a positive correlation between outgoingness and proficiency in French as a second language. However, they found that extroversion was only a significant factor for the late-immersion students who had one year of exposure to French. The students who had been surrounded by French since kindergarten did not seem to need the extra push of an extroverted personality. This would suggest that length of exposure to the second 
language may be connected to the extroversion/introversion issue. Certainly no one would ever assert that quiet individuals have less of a command over their native language than do more extroverted people. This same principle would seem to hold true for a second language immersion situation, where the more reticent and more outgoing students alike have had many years of intensive exposure to the second language, making personality less of a salient factor.

Suter used a natural elicitation task: students spoke spontaneously about the celebration of a holiday in their countries for a recording which could then be assessed for accuracy of pronunciation. But only pronunciation was measured, whereas all the rest of the studies undertook to assess many more components of language proficiency, and Strong hypothesizes that this may be why personality did not affect his results.

Cathcart et al. used NCL sampling measures such as storytelling and interviews to test their subjects. Their results showed that while extroversion was a significant variable at the grade one and two levels, it did not influence the language proficiency of the kindergarten children. The researchers account for this difference by noting that in the grade one and two classes, which were oriented much more towards individualized work, the more outgoing students would be able to create more opportunities for interaction, while the kindergarten class already provided many more situations for communication due to its cooperative structure. Thus the set-up of the classroom may be related to whether extroverted students will be favoured in the language learning situation. This leads up to the final section dealing with the results of the studies: the structure of the language classroom.

\section{THE STRUCTURE OF THE CLASSROOM}

Cathcart et al. found that extroversion was a salient factor for students who were studying a second language in a formal, structured learning environment. On the other hand, Smart and co-workers found that introverted students were favoured in their study, which consisted entirely of highly structured classes with much frontal teaching and little student interaction. How can we explain this contradiction?

Wong-Fillmore suggests that the difference may lie in the fact that Cathcart and colleagues dealt with children, while Smart et al. looked at adult subjects. She puts forth a further factor involved in extroversion among children: whether the pupils are adult-oriented or peer-oriented. Those who were peer-oriented may have been quite extroverted by nature; however they focused all their conversational energies on their classmates, who were also inexperienced learners of the second language. Those who were adult-oriented concentrated on the teacher, who was the principal 
source of second language input in the "open-plan", group-centred classroom.

\section{SUMMARY AND CONCLUSIONS}

The foregoing discussion has revealed a number of intertwined factors in the question of extroversion and its relationship vis-a-vis second language learning. The language assessment instrument, the structure of the class, the immersion situation, and the child's tendency to be oriented towards peers or adults may all be contributing factors to the influence of outgoing behaviour on second language learning. More studies need to be done in this area to investigate the interplay of these various contributing variables. In the meantime, we can say that it seems that extroversion does have some bearing on second language learning, although the exact nature of this relationship is still blurry and may be influenced by various contributing factors. More controlled research must be carried out in this area in order to attempt to separate the variables which are at play in the question of the influence of an extroverted personality on second language learning.

\section{IMPLICATIONS FOR THE LANGUAGE CLASSROOM}

How can we make use of the studies on extroversion and second language learning in our classroom teaching? It has been suggested that since extroverts may have a propensity for language learning, that teachers encourage the more reticent students to "come out of their shells" and participate more in the language classroom. While every teacher would agree that enthusiastic participation should be a goal to strive for in the classroom, there is only so far that we can take this practice. Littlewood (1983) expresses his reservations regarding the animation of students in the classroom. He feels that there is a limit to how far one can encourage the shy learner to verbalize, so as not to interfere with his personality and its natural expression in the new language. Brown (1973) also expresses his hesitation over the "cult of extroversion" in Western society. Extroversion is deemed to be a positive trait in our culture; however it may be less so in others, for example in Oriental societies.

Since many students are reserved, whether for cultural or individual reasons, Brown feels that it is not wise to test for proficiency solely on the basis of oral skills. A better overall picture of second language facility would be built up using listening comprehension, reading and writing measures, as well as oral elicitation procedures. This would give the less extroverted students more chances to demonstrate their capabilities in the second language, in ways in which they feel more comfortable. 
Many of the studies do point to the fact that opportunities for communication in the second language, especially with native speakers, should be encouraged among the quieter students, in order to provide them with plenty of comprehensible input, as well as with chances to practise expressing themselves in the new language. An experimental method designed to do just this was developed and tested by Johnson (1983).

Johnson termed her technique Inter-Ethnolinguistic Peer Tutoring (IEPT). She paired limited English-speaking pupils with native Englishspeaking partners and gave one child from each pair various tutoring tasks, such as explaining or teaching an activity in areas like cooking or art. The tutors then had to communicate the information to their partners and instruct them in completing the task. The experimental program continued for five weeks, during which time the roles of tutor and learner were constantly exchanged between the two partners. Johnson found that the children in the treatment group interacted more in English and significantly increased their mastery over English vocabulary as a result of the peer-tutoring experience, as compared to the control group which did not experience the IEPT treatment.

This technique shows promise for use in the second language classroom with both children and adults. It can help to provide comprehensible input from a source other than the teacher, especially for the peer-oriented children, who would otherwise lose out because of their preference for talking with their peers rather than with the teacher. It helps to overcome the problems associated with the teaches-fronted classroom. And, it may encourage more retiring students to speak more freely, since their utterances will not be open to the scrutiny of the entire class, but will constitute a private dialogue between the students and their partners, taking place so that they can accomplish a task together.

It has been suggested (Chastain, Cathcart et al.) that one possible way of dealing with personality differences in the classroom would be to stream students according to whether they are more or less outgoing, or alternatively to provide for more individualized instruction to match individual students' personality styles. This does not seem to be the prudent approach in tackling this aspect of second language learning. First, the evidence is not yet conclusive regarding the influence of an extroverted personality on second language learning to warrant such a step. Second, in view of the fact that there are many other factors to take into consideration when forming classes, such as level of proficiency, optimal class size, and various teaching methods, it hardly seems desirable to introduce yet another reason for fragmenting second language classes.

A better way of approaching the problem would be to provide as much variety in the classroom as possible to ensure that all personality types are catered to in some measure. A lively mix of frontal teaching, group study, 
pair work and individual learning in all of the four language skills is our best insurance for providing optimal learning conditions for all of our students. Inclusion of techniques such as Johnson's peer tutoring procedure in the classroom program will provide even more aid for students who are less inclined to verbalize. An awareness of the views of various cultures towards extroverted behaviours can be useful to the teacher as well. With the profusion of innovative teaching methods available, we must be leery of jumping on any particular teaching bandwagon because it may turn out that we are not giving our students a balanced language learning experience, which should be the goal in every classroom.

\section{FOOTNOTE}

1. The author wishes to thank Dr. Birgit Harley for her comments on an earlier version of this paper.

\section{REFERENCES}

Brown, H. D. (1973). Affective variables in second language learning. Language Learning, 23, 231-244.

Cathcart, R. W., M. A. Strong, and L. W. Fillmore. (1979). Social and linguistic behaviour of good language learners. In C. Yorio, K. Perkins, and J. Schacter (Eds.). On TESOL '79, Washington D.C.: TESOL, 267-274.

Chastain, K. (1975). Affective and ability factors in second language acquisition. Language Learning, 25, 153-161.

Crowne, D. P. and D. Marlowe. (1964). The Approval Motive: Studies in Evaluative Dependence. New York: Jon Wiley \& Sons.

Cummins, J. (1980). The cross-lingual dimensions of language proficiency: Implications for bilingual education and the optimal age issue. TESOL Quarterly, 14, 175-87.

Eysenck, H. J. and S. B. G. Eysenck. (1963). Eysenck Personality Inventory. San Diego: Educational and Industrial Testing Service.

Heist, P. and G. Yonge. (1962). Omnibus Personality Inventory. New York: The Psychological Corporation.

Johnson, D. M. (1983). Natural language learning by design: A classroom experiment in social interaction and second language acquisition. TESOL Quarterly, $17,55-67$.

Krashen, S. (1981). Second Language Acquisition and Second Language Learning. Oxford: Pergamon Press.

Littlewood, W. T. (1983). Contrastive pragmatics and the foreign language learner's personality. In Sajavaara, K. (ed.). Cross-language Analysis and Second Language Acquisition, Vol 1. Jyvaskyla, Finland: University of Jyvaskyla, 179-187. 
Naiman, N., M. Frohlich, H. Stern, and A. Todesco. (1978). The Good Language Learner. Research in Education No. 7. Toronto: Ontario Institute for Studies in Education.

Pritchard, D. F. L. (1952). An investigation into the relationship between personality traits and ability in modern languages. British Journal of Educational Psychology, 22, 147-148.

Rossier, R. (1976). Extroversion-introversion as a significant variable in the learning of oral english as a second language. $\mathrm{Ph}$.D. Dissertation, University of Southern California.

Scheibner-Herzig, G., A. Thiele, G. Jelinek and S. Kokoschka. (1984). A study of foreign language achievements and personality variables in 15-year-old pupils. ITL Review of Applied Linguistics, 65, 43-56.

Smart, J. C., C. F. Elton and C. W. Burnett. (1970). Underachievers and overachievers in intermediate French. Modern Language Journal, 54, 241258.

learning. Language Learning, 26, 233-253.

Swain, M. and B. Burnaby. (1976). Personality characteristics and second language learning in young children: A pilot study. Working Papers on Bilingualism, 11, 76-90.

Tucker, G. R., E. Hamayan, and F. Genesee. (1976). Affective, cognitive and social factors in second-language acquisition. Canadian Modern Language Review, 32, 214-226.

Wong-Fillmore, L. (1983). The language learner as an individual: Implications of research on individual differences for the ESL teacher. In M.A. Clarke and J. Handscombe (Eds.). ON TESOL '82, Washington, D.C.: TESOL, 157-173.

\section{THE AUTHOR}

Paula Kezwer is a doctoral candidate in language education at the Modern Language Centre, Ontario Institute for Studies in Education. She has taught ESL at Seneca College, Toronto, and at the Hebrew University of Jerusalem and Tel-Aviv University, both in Israel. Presently she is with the North York Board of Education. 